\title{
Fuzzy set approach to calibrating distributed flood inundation models using remote sensing observations
}

\author{
F. Pappenberger ${ }^{1, *}$, K. Frodsham ${ }^{2}$, K. Beven ${ }^{1, * *}$, R. Romanowicz ${ }^{1}$, and P. Matgen ${ }^{3}$ \\ ${ }^{1}$ Hydrology and Fluid Dynamics Group, Environmental Science, Lancaster University, Lancaster, LA1 4YQ, UK \\ ${ }^{2}$ JBA Consulting, The Brew House Wilderspool Park, Greenall's Avenue Warrington WA4 6HL UK \\ ${ }^{3}$ Département en Environnement et Agro-Biotechnologies, Centre de Recherche Public Gabriel Lippmann, Luxembourg \\ *now at: the European Centre For Medium-Range Weather Forecasts, Shinfield Park, Reading, UK \\ ** currently at: Geocentrum, Uppsala University, Villavägen 16, 75236 Uppsala, Sweden
}

Received: 8 March 2006 - Published in Hydrol. Earth Syst. Sci. Discuss.: 15 August 2006

Revised: 14 November 2006 - Accepted: 5 December 2006 - Published: 17 January 2007

\begin{abstract}
The paper presents a methodology for the estimation of uncertainty of inundation extent, which takes account of the uncertainty in the observed spatially distributed information and implements a fuzzy evaluation methodology. The Generalised Likelihood Uncertainty Estimation (GLUE) technique and the 2-D LISFLOOD-FP model were applied to derive the set of uncertain inundation realisations and resulting flood inundation maps. Conditioning of the inundation maps on fuzzified Synthetic Aperture Radar (SAR) images results in much more realistic inundation risk maps which can better depict the variable pattern of inundation extent than previously used methods. It has been shown that the evaluation methodology compares well to traditional approaches and can produce flood hazard maps that reflect the uncertainties in model evaluation.
\end{abstract}

\section{Introduction}

A large part of the world population is at risk of flooding (Dilley et al., 2005) and needs reliable estimation of potential extent of flood inundation. In many cases this risk is estimated with the help of flood inundation models, which have to be evaluated in order to be proven reliable. Suitable data for evaluating flood inundation models may exist in the form of internal hydraulic measurements such as discharge and stage, ground surveyed inundation extent measurements or aerial photographs and remotely sensed images (Horritt and Bates, 2003; Pappenberger et al., 2005, 2006a, 2007). Continuous data such as local discharge and stage measurements may be quantitatively compared with model predic-

Correspondence to: F. Pappenberger

(florian.pappenberger@ecmwf.int) tions using statistical methods based upon the sum of squared errors or more advanced techniques to provide an evaluation on how well the model is performing, with respect to internal flow hydrographs (Aronica et al., 1998; Hunter et al., 2005a; Romanowicz and Beven, 2003). However, while it is reassuring to know that an inundation model is a good predictor of internal hydraulic properties this does not necessarily imply that the model is always a good predictor of inundation extent (Pappenberger et al., 2005). A key element of any evaluation process is that model performance should be calibrated or conditioned on criteria that are closely linked to the purpose of the modelling exercise. This implies that inundation models, which are to be used to predict inundation extent and flood risk, are best conditioned on inundation extent data. Whilst this is standard practice in many flood inundation studies (e.g. Bates et al., 2006; Horritt, 2006; e.g. Yu and Lane, 2006), it may be argued that comparing modelled and observed spatial patterns is of limited use for determining flood risk/hazard. The study by Thieken et al. (2005), for example, demonstrates that water level, flood duration, and contamination are the most influential factors on building and content damage. In principle, of course, we would hope that physically based models should still be able to reproduce all the required variables with reasonable accuracy (for a further discussion see Pappenberger et al., 2006a) including any observations of flow depths or velocities. However, such data are only rarely available during flood events and this paper will focus only on evaluating predictions of the spatial pattern of inundation as estimated from remote sensing data.

Remotely sensed images, most notably those obtained using Synthetic Aperture Radar (SAR) sensors, are capable of recording inundation extent across large areas of floodplains. The value of such data for the modelling calibration exercise

Published by Copernicus GmbH on behalf of the European Geosciences Union. 

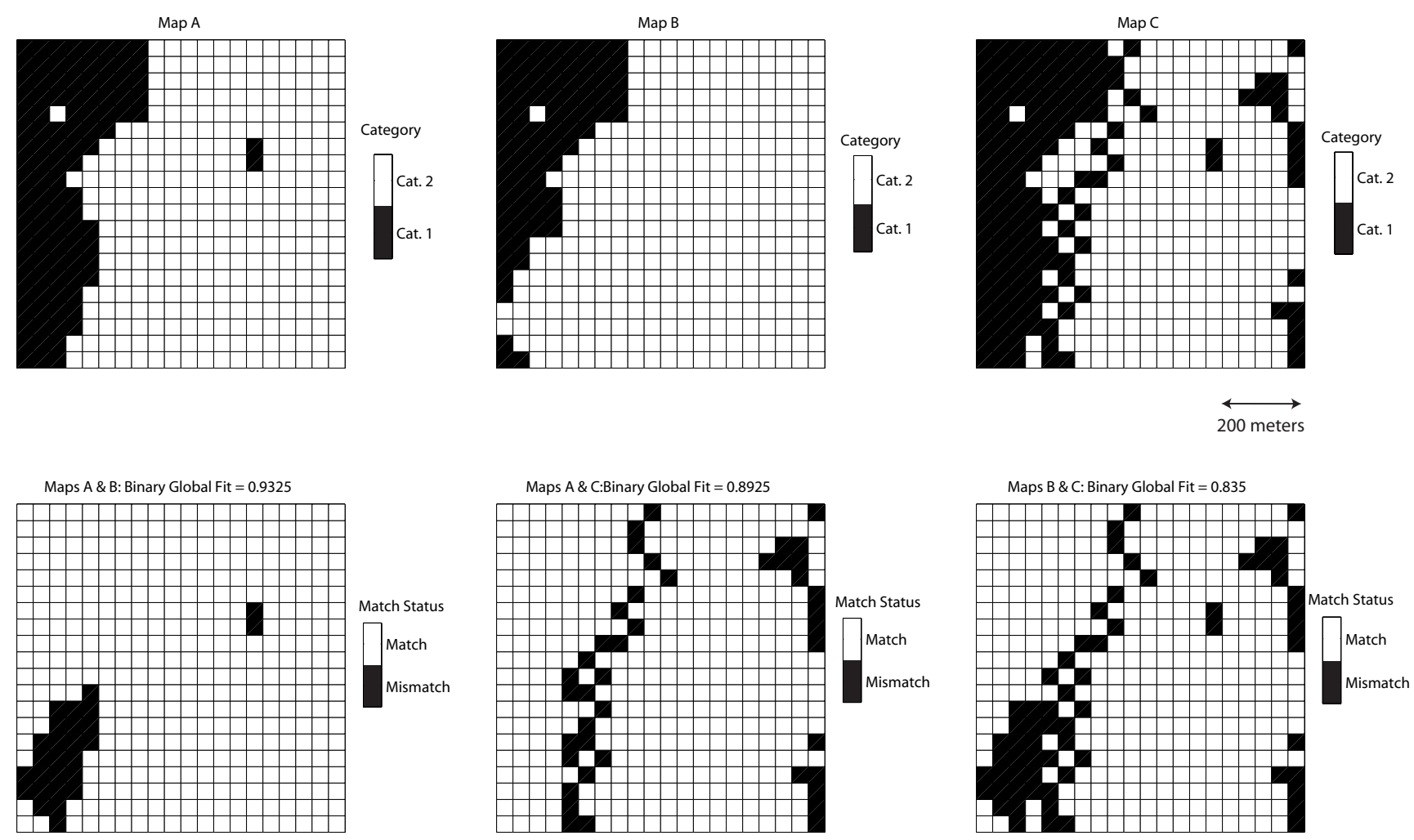

Fig. 1. An example of map comparison using a discrete, binary matching system. Maps A, B and C can be regarded as interpretations of the same data set in which there is uncertainty in the category status across zones delineated. The lower maps show how the global fit (assessed as the ratio of matching cells to the total number of cells) cannot represent the uncertainty in cell status. The match between A and B may be an overestimate due to coincidental matching of categories within the zones of uncertainty while the match between $\mathrm{B}$ and $\mathrm{C}$ may be an underestimate due to poor matching of cells within the uncertainty zones.

is still being explored (Horritt et al., 2001; Matgen et al., 2007). As yet there is no commonly accepted or general standard methodology for performing comparisons on 2-D spatial data (Hagen, 2003; Schumann et al., 2005). Previous 2$\mathrm{D}$ inundation based modelling exercises have adopted a discrete matching scheme based on separating cells into binary categories of wet or dry (Aronica et al., 2002; Bates and De Roo, 2000; Horritt and Bates, 2001; Hunter, 2006). This approach requires the data to be divided into discrete categories separated by well defined, deterministic (crisp) boundaries, a process that can only be successfully applied if there is a high degree of confidence in the data (Cheng et al., 2001). In inundation modelling there is often considerable uncertainty in interpreting the true extent of inundation from satellite data because of the variations in backscattering and image speckle that can arise from features like waves and emergent structures and vegetation (Horritt et al., 2001; Matgen et al., 2004). Uncertainties will also arise from the interpretation of inundation extent from model predictions. Rather than being able to delineate a crisp shoreline it is normally only possible to determine a zone within which we expect any shoreline to lie. Representing inundation data by discrete, binary inunda- tion maps might then lead to variations in model fit within the zone of uncertainty that encloses the true shoreline (Fig. 1). One way of constraining performance variations that may arise from forcing uncertain data to take discrete values is by implementing fuzzy mapping techniques that enable the retention of information on the level of confidence at which data categories are represented (Cheng et al., 2001; Hagen, 2003; Power et al., 2001). Fuzziness has previously been incorporated into a number of performance measures during inundation modelling exercises (Aronica et al., 1998; Pappenberger et al., 2005; Romanowicz and Beven, 2003) but to date has not been used to address spatial uncertainties in the evaluation of 2-D inundation models using satellite images of flooding.

The objective of this paper is to present a methodology for estimating the uncertainty in predictions of flood inundation, in a novel way that uses fuzzy set approaches to take account of uncertainty in the available remote sensing observations of inundation as well as different sources of uncertainty in applying the model.

The methodology applies the 2-D LISFLOOD-FP model within a Generalised Likelihood Uncertainty Estimation 
(GLUE) framework to derive the possibility distribution of inundation extent for an $8 \mathrm{~km}$ reach of the River Alzette, Luxemburg.

\section{Description of methodology and case study}

\subsection{The Alzette study area}

The area considered in this study is an $8 \mathrm{~km}$ long reach of the Alzette River in Luxembourg, along which the river meanders gently across a floodplain that ranges from approximately $250 \mathrm{~m}$ to one kilometre in width (Fig. 2). Crosssectional surveys which include information on both channel width and depth were available at 74 locations along the reach. Upstream stage measurements are routinely recorded and allow the estimation of approximate upstream hydrographs via rating curves. A medium scale (1 in 5 years) flood event took place in January 2003. Discharge with the peak around $67 \mathrm{~m}^{3} \mathrm{~s}^{-1}$ and the extent of inundation was recorded by Envisat satellite at a time close to this estimated peak discharge to provide a suitable 2-D data set for evaluating model performance with respect to inundation extent. The ENVISAT Advanced Synthetic Aperture Radar (ASAR) scene (spatial resolution of $12.5 \mathrm{~m}$ ) is acquired at an incidence angle of $35^{\circ}$ and in alternating polarisation mode (VV/VH). The ASAR on board ENVISAT, operating at Cband $(5.3 \mathrm{GHz})$, is an advanced version of SAR instruments on board the ERS-1 and ERS-2 satellites as it features enhanced capability in terms of coverage, range of incidence angles, polarisation, and modes of operation (ESA, 2004).

\subsection{Implementing LISFLOOD-FP for the Alzette catch- ment}

The 2-D flood inundation model used in this study, LISFLOOD-FP, was developed as a model of flood plain dynamics that could be readily integrated with high resolution GIS topographic data (Hunter et al., 2005b). The advantages and disadvantages of this particular model are not discussed here as they are of minor importance for the objective of this paper. Here we concentrate on a methodology of evaluating uncertain spatial flood inundation maps. Other distributed models, such as TRIM2D, TELEMAC, RMA2 or TUFLOW, could have been used (for a discussion of various raster based models see Leopardi et al., 2002). The reader is referred to Hunter et al. (2005b) for a detailed description of the model and its implementation.

LISFLOOD-FP requires a variety of information to generate inundation predictions. Digital Elevation Maps (DEM's) were initially obtained for the area at resolutions of 2, 20, 50 and $100 \mathrm{~m}$ to establish uncertainties and sensitivities of the predictions with respect to grid resolution (Hardy et al., 1999). During preliminary testing the time taken to evaluate the full flood event hydrograph at the scale of the $20 \mathrm{~m}$ DEM (in excess of $6 \mathrm{~h}$ on a standard Pentium $2 \mathrm{Ghz}, 512 \mathrm{MB}$

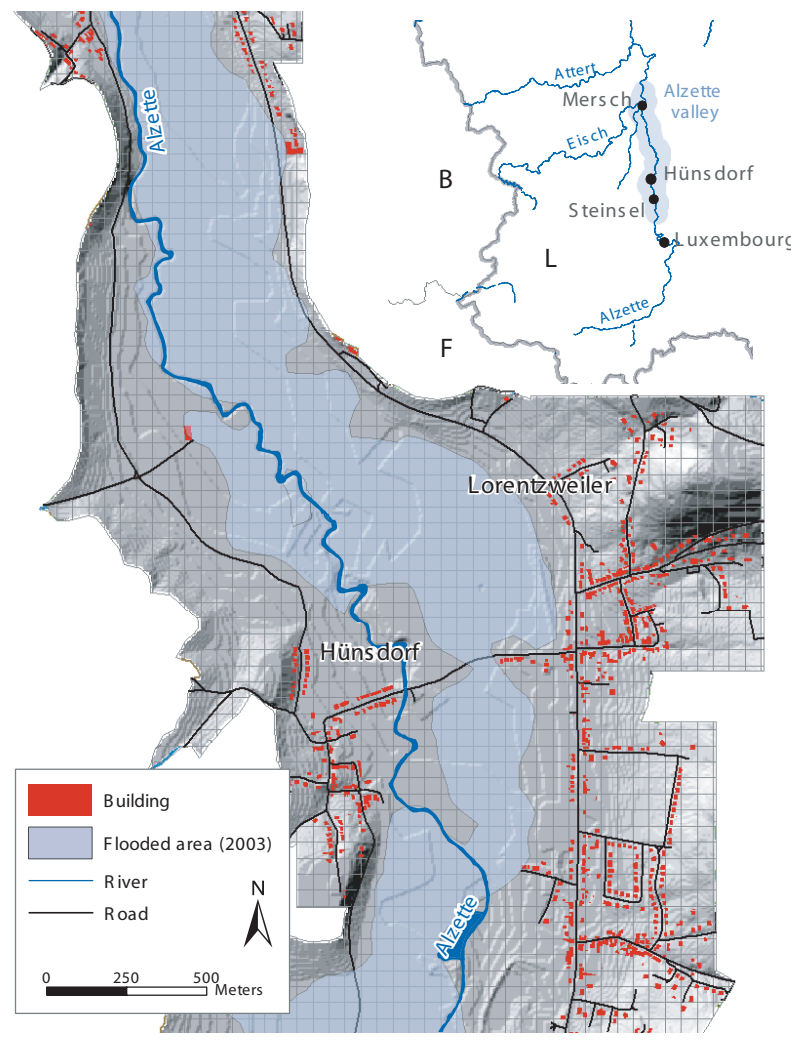

Fig. 2. The study area. The Alzette River and adjacent buildings superimposed upon a $50 \mathrm{~m}$ resolution DEM of the floodplain.

$533 \mathrm{MHz}$ DDR2 SDRAM) was considered inappropriate for the multiple runs that would be required during a full uncertainty analysis. Consequently, the $50 \mathrm{~m}$ DEM, which resulted in simulations of approximately $30 \mathrm{~min}$ under similar conditions, was selected. This resolution is sufficient for the purpose of this paper, i.e. demonstration of the concept of using uncertain inundation observations. It is consistent with the findings of Bates and De Roo (2000), also using LISFLOOD-FP, who have shown that a $50 \mathrm{~m}$ resolution grid marked optimal efficiency during their inundation modelling exercises for floodplains with a similar spatial scale and that only limited additional performance could be gained from going down to finer resolutions (although we believe this is data and reach specific). Channel information from the crosssectional surveys was used in the model setup. Internal structures such as bridges have been ignored in this study and the reader is referred to Pappenberger et al. (2006b) for a comprehensive study, which includes the uncertainty of internal boundaries. Use of the kinematic wave equation for routing channel flow within LISFLOOD-FP means that a constraint must be imposed so that the channel slope is always positive in the downstream direction. 
Table 1. Parameters included in the uncertainty analysis and ranges sampled.

\begin{tabular}{lll}
\hline Parameter & Sampling Range & Distribution \\
\hline Floodplain Roughness & $0.05-0.3$ & Log-uniform \\
Channel Roughness & $0.01-0.2$ & Log-uniform \\
River width & $\pm 10 \%$ & Uniform \\
Outflow Roughness & $0.01-0.4$ & Log-uniform \\
Inflow Magnitude (chosen among a set of 20 contrasting hydrographs) & $1-20$ & Uniform \\
Initial error of channel depth on the first cross-section & $\pm 15 \mathrm{~cm}$ & Uniform \\
Standard deviation for cross-section error, with mean taken from previous cross-section & $0.01-0.1$ & Uniform \\
\hline
\end{tabular}

\subsection{Uncertainty analysis}

A common feature of inundation models is that the values of specific factors (e.g. upstream and lateral discharges, topographic data, floodplain infrastructure, or frictional coefficients) can rarely be known sufficiently well to produce model predictions that agree unequivocally with available evaluation data (Kavetski et al., 2006; Pappenberger et al., 2005). Pappenberger and Beven (2006) have discussed the implications of not taking account of these issues. Analysis of flood risk is, therefore, best embedded in an uncertainty framework. Experience in past modelling studies that have looked beyond trying to simply find an "optimum" model fit to the available observations suggest that there may well be a large number of parameter sets across the parameter space that are able to map model predictions to the observed data to an acceptable level of performance (e.g. Horritt and Bates, 2001; Romanowicz and Beven, 2003; Romanowicz et al., 1996). This is consistent with the concept of equifinality in environmental modelling (Beven, 2006). The GLUE (Generalised Likelihood Uncertainty Estimation) methodology of Beven and Binley (1992), accepts the notion of equifinality and attempts to find those feasible models that provide acceptable fits to any available observations data. These multiple models can then be used to estimate the level of confidence that can be placed upon a range of model predictions rather than concentrating on a single "optimum" prediction. Previous applications of the GLUE procedure to flood inundation uncertainty estimation are given in Aronica et al. (2002, 1998); Bates et al. (2004); Pappenberger et al. (2006a); Romanowicz and Beven (2003); Romanowicz et al. (1996).

\subsection{Allocating prior parameter distributions in GLUE}

The initial stage of the GLUE procedure involves choosing a model and delineating the parameter space that is to be mapped by both listing the uncertain input variables and parameters and specifying their ranges and distributions (a summary is given in Table 1). All factors/parameters in this analysis have to be understood as effective factors/parameters (for a discussion of this issue see Beven,
2006; Pappenberger et al., 2006a).The channel and floodplain roughness coefficients are known to be a major source of uncertainty in flood inundation models (Aronica et al., 2002, 1998; Horritt and Bates, 2001; Pappenberger et al., 2005) and may vary across a wide range of feasible values. The choice of sampling strategy implies the choice of prior distributions for the parameters together with their ranges of variability. It is performed in a recursive way following the preliminary sensitivity analysis of the model response surface (Romanowicz and Macdonald, 2005). The choice of prior distribution is subjective and should take into account physical meaning of parameters as well as the model behaviour. Therefore, the channel friction was allowed to vary between 0.01 and 0.2 and the floodplain friction between 0.05 and 0.3 , with lower boundary corresponding to the typical Manning friction values. The downstream boundary condition was approximated by uniform flow and therefore required the specification of an additional roughness value.

Channel widths along the reach were allowed to vary by $\pm 10 \%$ from the values obtained from the channel surveys. In order to replicate the uncertainty that is believed to be inherent in using stream hydrographs as model inputs (Pappenberger et al., 2006a), a set of 20 contrasting hydrographs was prepared that were consistent with the available stage measurements via rating curves. The influence of uncertainty in representation of flood plain and channel geometry depends on the role the floodplain plays in the routing of the flow (see discussion in Werner et al., 2005a). For example, Aronica et al. (1998) that uncertainty in flood plain topography is important in controlling mode performance, whereas Werner et al. (2005b) and IRMA (IRMA, 2002) seem to prove the opposite. In this example, we concentrate on the uncertainty in the channel cross-section and not the floodplain geometry as we assume that the channel conveyance and embankment heights are the major controls for the flood extent in this river reach.

The depth of the channel bed and the slope have been derived from 73 cross-sections, which have been included in the LISFLOOD-FP model. The model approximates the channel conveyance from channel cross-sections similar to more traditional one-dimensional models, and interpolates 
the channel geometry between these cross-section breaklines. It is not possible to introduce independent errors for the channel depth on all 73 cross-sections measured due to computational constraints of sampling such a high dimensional. Therefore, in order to minimise the dimension of the parameter space. Therefore, a simpler approach based on, while modelling the inherent depth uncertainty, only two parameters has been used to specify this uncertainty. For each model simulation an error of the channel depth has been assigned to the first cross-section. The errors of the following cross-sections have been derived from a normal distribution with the error of the preceding cross-section as a mean. A positive slope has been enforced by re-sampling until this condition has been met. Thus only two parameters needed to be specified: the initial error and a variance. It is worth noting that a negative slope for the LISFLOOD-FP based on $50 \mathrm{~m}$ grid would be physically unrealistic. This paper does not use one single mean error for the depth of all channel cross-sections as we believe that this error is more variable and not necessarily always constraint from one section to the other.

The prior parameter distributions for the 7 parameters (see Table 1) were all defined as uniform distributions with the additional constraint that the channel and floodplain frictional coefficients were sampled so that the former could never exceed the latter (see Table 1). For the roughness parameters, because of the possibility of sampling over more than one order of magnitude, a log-uniform distribution was chosen to explore better the lower, more physically justified roughness values while still preserving the large range of their variability. This resulted in a prior distribution for roughness parameters skewed towards lower parameter ranges. A series of $\sim 28000$ simulations was performed using parameter values chosen at random from the designated ranges and results were saved as water depth maps at the time of satellite overpass. The total number of simulations has been sufficient to approximate the response surface without exceeding the acceptable time of computations.

\subsection{Discrete spatial performance measures}

A number of commonly used performance measures for the evaluation of inundation extent using a discrete, binary, matching system were computed in order to provide a basis with which the measure introduced in this paper could be compared. Cells that were categorised as either inundated or not inundated on both observed and predicted maps were grouped together to form a contingency table (Table 2) from which various criteria were evaluated using the formulae listed beneath the table. This is a common approach in the evaluation of spatial predictions in meteorological mod$\mathrm{els}^{1}$ and is now beginning to be applied in inundation mod-

\footnotetext{
${ }_{1}$ at http://www.metoffice.com/research/nwp/publications/nwp_ gazette/mar02/verif.html
}

Table 2. A contingency table for evaluating discrete binary inundation extent with the various performance measures used in the study defined below largely taken from Schumann et al. (2005).

\begin{tabular}{clcc}
\hline \multirow{2}{*}{ Contingency table } & \multicolumn{2}{c}{ Observed } \\
& & Inundated & Not inundated \\
\hline \multirow{2}{*}{ Forecast } & Inundated & $\mathrm{a}$ & $\mathrm{c}$ \\
& Not inundated & $\mathrm{b}$ & $\mathrm{d}$ \\
\hline
\end{tabular}

1 Hit: $a \div(a+b)$

2 Accuracy: $(\mathrm{a}+\mathrm{d}) \div \mathrm{n}(\mathrm{n}=$ number of cells $)$

3 False alarm rate $(\mathrm{f}): \mathrm{c} \div(\mathrm{c}+\mathrm{d})$

4 Odds: (hit $\div(1-$ hit $)) \div(f /(1-f))$

5 Threat score or $\mathrm{F}^{2}$ of Aronica et al. (2002): $\mathrm{a} \div(\mathrm{a}+\mathrm{b}+\mathrm{c})$

6 Modified threat score: $(a-c) \div(a+b+c)$

7 Bias: $(a+c) \div(a+b){ }^{1}$

8 Pierce Skill score: (Hit - False alarm rate)

elling (Hunter, 2006; Schumann et al., 2005). Some degree of confusion has arisen from both the sheer number of proposed measures and the fact that some of the measures have been used under different names, thus necessitating a careful examination of the formulae used in previous studies before making comparisons. The reader is referred to Hunter (2006) for an excellent in-depth discussion of the various measures.

In order to evaluate the discrete, binary performance criteria it was necessary to convert the model predicted water depths into a discrete binary inundation map. In common with the approach adopted in previous studies (e.g. Aronica et al., 2002) only cells with predicted depths greater than $10 \mathrm{~cm}$ were assumed to be inundated in order to reflect uncertainties in the exact shoreline location. For these discrete measures, the Envisat satellite image was converted to a binary inundation map using a statistically derived "snake" algorithm (Horritt et al., 2001) that creates an estimate of the shoreline location. This algorithm has been used to make the results of this study comparable with previous publications (see Hunter, 2006; Hunter et al., 2005a, and references therein). The 'snake' image was then converted to a $50 \mathrm{~m}$ resolution raster grid for direct comparison with the model predicted inundation maps. Finally, for this study, performance was averaged only across the set of cells that were subject to change in at least one model realisation, hence, disregarding all cells that were correctly predicted to be either wet or dry in all realisations. This group of cells represents the largest area that can be considered to be at risk of mis-prediction in the complete set of model realizations. This approach is comparable to the use of flood extent data in one-dimensional approaches (see e.g. Pappenberger et al., 2006a; Roux and Dartus, 2006). There is significant uncertainty in the classification of inundation from SAR imagery. In what follows, this uncertainty is taken into account in model evaluation. 


\subsection{Creating a fuzzy inundation map from the SAR data}

In order to apply fuzzy performance measures it was necessary to create fuzzy inundation maps from both the remotely sensed SAR data and the model predictions. The generation of the fuzzy map from the SAR data is based on the approach of Matgen et al. (2004) in which different backscattering properties were mapped to different categories of membership in inundation possibility that reflect different levels of confidence (high, medium, low and "no") in any particular area of the floodplain being inundated. Matgen et al. (2004) applied a simple threshold approach to quantify a fuzzy membership function of flooding along each crosssection which expresses the uncertainty of flooding extent. Profiles of pixel values at several cross sections of the river floodplain are drawn and confronted with the GPS control points of the maximum lateral flood extent. This allows the threshold value of the radar backscattering coefficient to be determined for the binary classification of flooded and nonflooded pixels. This approach provides the reference flood map. To reflect our lack of knowledge about the real flood extent, the threshold value of the radar backscattering is slightly changed to delineate other plausible flood maps. This uncertainty in inundation extent can be used directly in the creation of a fuzzy inundation map once the data have been converted into a raster map at the required resolution.

On a fuzzy map each cell is assigned a membership vector, $V$, of the form

$$
V=\left(\lambda_{\text {high }}, \lambda_{\text {medium }}, \lambda_{\text {low }}, \lambda_{\text {no }}\right)
$$

each element, $\lambda$, of which refers to one of the inundation categories on the map. The value assigned to each element is chosen to reflect the degree of belonging to that category with a value of 1 representing total membership and a value of 0 representing no membership. Spatial data in which the categories are considered to be totally disparate can be represented by a system of crisp vectors (Cheng et al., 2001; Hagen, 2003) in which the original map category is represented by a value of 1 and all other categories by 0 . Under the system depicted in Eq. (1), a cell classified as having a medium possibility of inundation would be represented as

$V_{\mathrm{CRISP}_{\text {medium }}}=(0,1,0,0)$.

The use of crisp vectors in a fuzzy system should be reserved only for cells in which there is little or no uncertainty in the categorization of that cell. The categories on the SAR inundation map are related in an ordinal sequence. Under these circumstances, relationships between categories can be represented by introducing fuzzy category vectors (Hagen, 2003), in which the values assigned to the individual elements of the vector reflect the level of similarity that an element is believed to bear to the original map category, which itself retains a value of 1 . For example, a cell located entirely within the high inundation category on the SAR map is more closely related to the medium inundation category than to the low and similarly more closely related to the low than the 'no' categories. Such a cell could be represented by the fuzzy category vector

$V_{\mathrm{CAT}_{\text {high }}}=(1,0.6,0.3,0)$

and the set of fuzzy category vectors that was used to populate the SAR map was

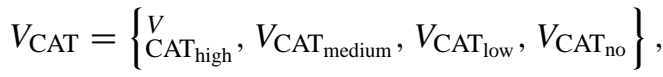

where

$V_{\mathrm{CAT}_{\text {high }}}=(1,0.6,0.3,0)$,

$V_{\mathrm{CAT}_{\text {medium }}}=(0.6,1,0.6,0.3)$,

$V_{\mathrm{CAT}_{\text {low }}}=(0.3,0.6,1,0.6)$,

$V_{\mathrm{CAT}_{\mathrm{no}}}=(0,0.3,0.6,1)$.

The system for assigning fuzzy category vectors had to be modified for cells in which more than one category existed on the original SAR map. A simple formula was used to weight the vectors according to the fractional area of the cell that was covered by different categories.

$$
\begin{aligned}
V_{\mathrm{CAT}}= & h(1,0.6,0.3,0)+m(0.6,1,0.6,0.3) \\
& +l(0.3,0.6,1,0.6)+n(0,0.3,0.6,1)
\end{aligned}
$$

where the coefficients $h, m, l$ and $n$ are the fractional areas covered by high, medium, low and no inundation categories respectively. In our example the modeled output and observed data do not share the same resolution. Although the same resolution is desirable, it was not possible due to computational demands. This problem could have been overcome by re-projecting the flood outline on a finer geometry (under consideration of the additional uncertainties) or by integrating these uncertainties into the evaluation measure. This is addressed by fuzzifing the model predictions as described in the following section.

\subsection{Fuzzifying the model predictions}

The model predictions consist of raster maps of water depth across the floodplain. However, our model predictions are based on $50 \mathrm{~m}$ cells, which currently ignore any sub-grid scale heterogeneity of the surface geometry. This can be partially overcome, by either applying the model on a finer scale, re-projecting the model results on a finer topography or introducing storage-conveyance relationships as in Romanowicz et al. (1996). Moreover, co-registration errors between modeled and inundated maps will exist. Fundamentally, a commensurability problem in the comparison of measured data and observed data remains (Beven, 2006). Only rarely will the modeled data be of same spatial and temporal resolution as the observed data. Therefore, in this paper we develop a 
methodology which can take account of this commensurability error and can be easily transferred to future applications.

LISFLOOD-FP predictions consist of a single depth value based upon the mean elevation within each raster cell. By using a fine resolution $(2 \mathrm{~m})$ DEM to generate a set of statistics (see Fig. 3) relating to the terrain distribution within each $50 \mathrm{~m}$ DEM cell, it was possible to gain an estimate of the likely extent of inundation within the cell. This allowed the construction of a subjective function (Fig. 3) by which the intercept of the locally predicted water surface on the terrain distribution across a cell is used to allocate a fuzzy category vector of the same type as shown in Eq. (4). If the predicted water depth for a cell is positive then the fuzzy category vector can be determined from that cell alone but if the predicted water depth is zero the water level has to be extrapolated from the mean water elevation in adjoining cells. The function illustrates the belief that if the whole of a cell is predicted to be inundated to a depth greater than $10 \mathrm{~cm}$ then there is a high possibility of that cell being inundated. Similarly, if the whole of a cell lies above the predicted water level in the immediate vicinity then it is assumed to have zero possibility of inundation. Medium and low inundation probabilities were subjectively assigned to differing ranges of partial inundation. The function illustrated in Fig. 3 can easily be modified if required to provide, for example, a scalar inundation likelihood index of between 0 (zero possibility of inundation) and 1 (very high possibility of inundation) or to further weight the membership values within each fuzzy category class. For example, a category of very high respective membership values of $(1,0,0,0)$ could be assigned to cells for which the depth prediction implies inundation of the whole of the cell by $0.5 \mathrm{~m}$ or more. For the purposes of this study the fuzzy category representation of the model predictions shown in Fig. 3 was deemed sufficient. Figure 4 illustrates a section of the fuzzy model map obtained from a single LISFLOOD -FP realization.

\subsection{Computing a global fuzzy performance measure}

Model performance within each cell for each realisation was evaluated using the standard similarity function, $S$, of Hagen (2003) that enables the comparison of two fuzzy category cells. For two fuzzy vectors $V_{A}$ and $V_{B}$ (of the form in Eq. 1) that represent the same cell location on maps $A$ and $B$, respectively

$$
\begin{aligned}
S\left(V_{A}, V_{B}\right)= & {\left[\left|A_{\lambda_{\text {high }}}, B_{\lambda_{\text {high }}}\right|_{\text {min }},\left|A_{\lambda_{\text {medium }}}, B_{\lambda_{\text {medium }}}\right|_{\text {min }},\right.} \\
& \left.\left|A_{\lambda_{\text {low }}}, B_{\lambda_{\text {low }}}\right|_{\text {min }},\left|A_{\lambda_{\text {no }}}, B_{\lambda_{\text {no }}}\right|_{\text {min }}\right]_{\text {max }} .
\end{aligned}
$$

$S$ is therefore the maximum value within the set obtained by evaluating the minimum of the two fuzzy vectors $V_{A}$ and $V_{B}$ on an element by element basis. $S$ lies between 0 for cells that are totally dissimilar in category across the whole of the cell and 1 for cells that are identical in category across the whole of the cell. As a consequence of the similarity val-

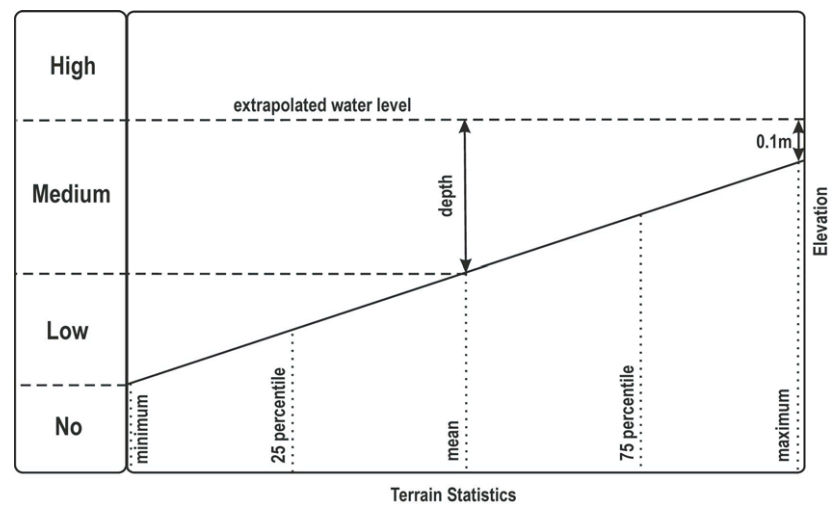

Fig. 3. A function relating model predicted water depths to fuzzy, inundation possibility, category vectors. The LISFLOOD predicted depth value from a cell or, if dry, from adjoining cells is used to calculate the water level across a cell and the intercept of this water level on the terrain statistics surface is used to allocate fuzzy category vectors. The pixel resolution is $50 \mathrm{~m}$.

ues used to populate the system of fuzzy category vectors in this study, small differences (one order of category or less) between observed and model predictions for a cell will lead to $S$ values of 0.6 or greater. Within the zone of uncertainty around expected shorelines such values may be considered a satisfactory measure of fit especially when one considers the uncertainties in the boundary locations between inundation categories that will result from using a function such as that in Fig. 3. Conversely, $S$ values less than 0.6 can be regarded as indicators of poor model performance for a cell. When plotted spatially the range of similarity values produced in a fuzzy comparison typically reveals more structure to the pattern of fit than discrete, non-fuzzy, comparisons (Power et al., 2001).

A global fuzzy performance measure, $G_{S}$, for each model realisation was obtained by averaging the standard similarity values obtained by comparing fuzzy SAR and fuzzy model maps across all cells, $i$, within a designated area of the raster maps. For this study $G_{S}$ was averaged across all cells that possessed a standard similarity value, $S$, of less than 1 in at least one of the model realisations, which represents the whole of the area that was prone to change across the set of realisations. For a designated inundation prone area of $n$ cells

$G_{S}=\frac{\sum_{i=1}^{n} S\left(V_{\mathrm{OBS}, \mathrm{i}}, V_{\mathrm{MOD}, \mathrm{i}}\right)}{n}$.

\section{Results and discussion}

This section will initially discuss the results of the comparison of the proposed fuzzy evaluation methodology with the traditional measure of fit. It then proceeds to present the 

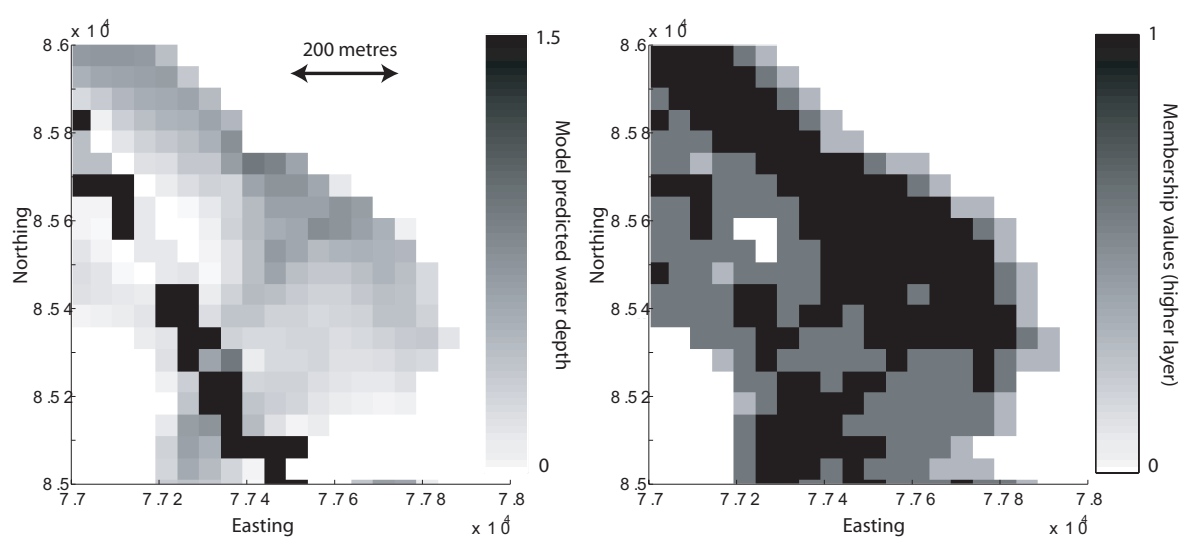

Fig. 4. A diagram illustrating the transformation from model results for a single LISFLOOD-FP realisation (a) to the fuzzy interpretation map of inundation categories (b) arising from the use of the subjective function illustrated in Fig. 3. Only the high inundation possibility layer is illustrated. The cell size is $50 \mathrm{~m}$.
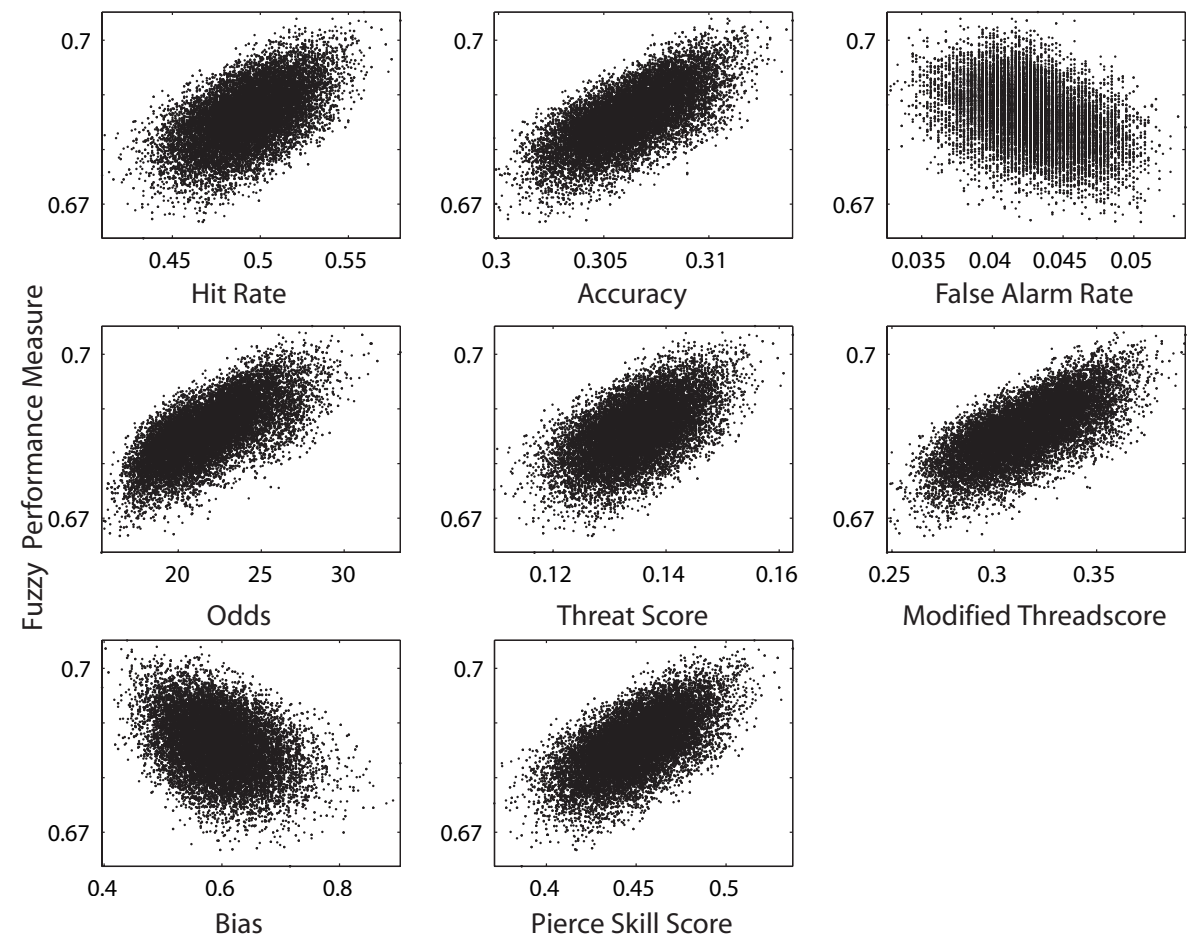

Fig. 5. Correlation plots between fuzzy global performance and selected discrete binary performance measures for the full set of LISFLOODFP realisations.

results of the uncertainty analysis and resulting flood hazard maps.

3.1 Comparison of fuzzy performance measure to previously used performance measures

A subset of traditional measures has been used in this comparison. There is a blurred correlation between the fuzzy performance measure, $G_{S}$, and most of the discrete, binary inundation measures (Fig. 5). This expresses the additional error source this measure is accounting for. It is apparent that $G_{s}$ has a smaller range than traditional scores. In artificial tests (not displayed here) this range was much larger and thus is a result of the specific characteristics of this domain. The fuzzy performance measure and all other measures are generally positively correlated suggesting that it is not inconsistent with any of the more traditional approaches to model evaluation. Therefore, it can be argued that the measure behaves 

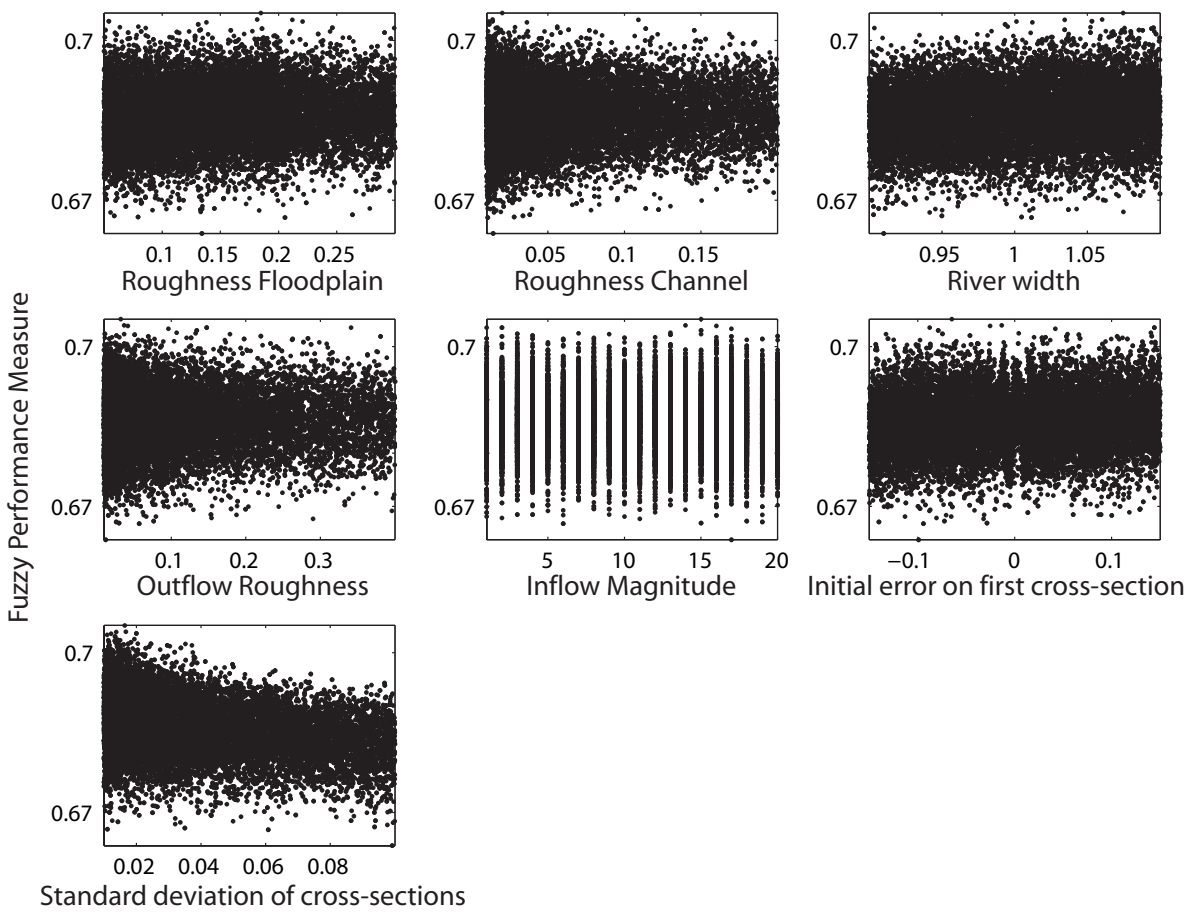

Fig. 6. Dotty plots of the model results. On the $y$-axis is the model performance and the $x$-axis the model parameters. Each dot represents one model simulation. The inflow magnitude has been derived from 20 distinct rating curves, which have been sorted according to magnitude at the time of the observation taken with 20 representing the maximum.

"well" in comparison to traditional approaches. However, in contrast to the traditional measures the fuzzy measure in this paper includes the uncertainties in the observations and thus has the potential to include a higher information content. Most of the scatter plots display a similar two dimensional pattern, however, the individual plots have different point densities. Comparisons of plots between the various measures are shown by Schumann et al. (2005) and Hunter (2006) and are not part of this analysis. Schumann et al. (2005) and Hunter (2006) have both recommended the Modified Threat Score as the measure with the most potential in the discrete evaluation of 2-D inundation models. However, their analysis of the performance measure has been computed using maps that were created using the SNAKE algorithm (Horritt, 1999) to extract the flood outlines. The SNAKE algorithm, as well as the Modified Threat Score, favours the same type of flooding pattern (large areas in contrast to a fragmented floodplain).

It should be noted that Hunter (2006) also suggests the use of other measures and describes the applicability and limitation of each measure individually. For example, he rejects the use of the Accuracy Measure, as it provides a too optimistic assessment of the flood model, and the application of the Pierce Skill Score as it does not properly penalise overprediction. In that paper the usefulness/applicability of each measure is evaluated according to the individual physical implications. Hunter (2006) emphasizes a key point: a perfor- mance measure should be used according to the purpose of the model and the quality of the available data.

These traditional measures, however, ignore both data quality and incommensurability issues and therefore may not reflect the real information content of the observations in conditioning the model predictions. The purpose of the modelling exercise is here defined as getting the average performance of the entire flood domain, which can be questioned as a modelling goal for a flood risk model (for a discussion see Pappenberger et al., 2007). Figure 5 demonstrates that the novel fuzzy performance measure can give similar results to the traditional measures, while taking account of the error in the evaluation data.

\subsection{Parameter uncertainty}

In Fig. 6 the parameter uncertainty of the LISFLOOD-FP model is plotted. On the $y$-axis is the fuzzy measure performance and on the $\mathrm{x}$-axis are the parameters. Each dot represents one simulation. The "Floodplain Roughness", "River width", "Inflow Magnitude" and the "Initial error on first cross-section" indicate an equifinality in fitting the (non-error free) observations. The "Channel Roughness", "Outflow Roughness" and the "Standard deviation for crosssection error" seem to have some tendency towards an optimum at lower values. Possible explanations for these patterns are given in Table 3. However, no convex surfaces can 
be observed in these projections. The model is responding in a highly complex way to the sampled parameters and the sample size seems to be still too low. Indeed, the "Outflow Roughness" has two distinct "optimal" simulations at higher values, which would have been most probably not found in an optimisation framework. It is apparent from the model implementation that certain parameters such as channel roughness and cross-section depth or inflow discharge should interact with each other in producing good fits to the observations. However, the results did not reveal any higher order correlations of this sort. This may be the result of undetected numerical errors, the complexity of the model used, or the effect of the error in the observations.

We applied GSA to better explore the shape of parameter response surface and compare the results with those obtained using traditional, crisp binary inundation maps. Factor or parameter sensitivity analysis should be part of every uncertainty analysis of flood inundation models. It enhances the understanding of model results by illustrating which factors are the most important and suggesting the factors which should receive greater attention to reduce model uncertainty. We apply the Global Sensitivity Analysis (GSA) (Saltelli et al., 2004) in order to compare the results obtained using traditional binary maps with the results obtained using fuzzified satellite images. In this paper the SOBOL-SDP sensitivity analysis (Ratto et al., 2004) will be applied. The method defines factor sensitivity by estimating the contribution of each factors to the variance of model outputs (so called first order sensitivity). Table 4 summarizes the result of the SOBOL analysis for each performance measure. With all performance measures only two parameters exhibit any sensitivity ("Standard deviation for cross-section error" and "Channel Roughness"). However, the sensitivities are very small as has already been seen in Fig. 6. It can be seen that the fuzzy measure behaves similar to the accuracy or modified thread score measure.

The example of river width demonstrates that factor equifinality and sensitivity depends, as expected, on the performance measure chosen. It should not be concluded from this table that one performance measure is better for certain kinds of calibration (e.g. optimisation) as the meaning of each performance measure has to be the predominant selection factor and should follow from the specific goal of the modelling. This table mainly illustrates that the new fuzzy performance measure compares well to the traditional measures and thus gives us further assurance regarding its adequacy.

\subsection{Flood inundation map}

Spatial predictions of inundation extent are best illustrated by generating 2-D maps that depict the likelihood of inundation across a floodplain. This can be achieved by weighting the cells of each behavioural realisation in proportion to the global performance of that realisation (Aronica et al., 2002). In order to generate an inundation possibility map condi- tioned on $G_{S}$ (Eq. 7), Eq. (10) was applied to each fuzzy category in turn (see Eq. 4).

$$
V_{i}^{\text {flood }}=\frac{\sum_{j}\left(S_{i, j} \times G_{S_{j}}\right)}{\sum_{j} G_{S_{j}}}
$$

where $V_{i}^{\text {flood }}$ is the likelihood or possibility of flooding in cell $i, S_{i, j}$ is the standard similarity value for cell $i$ in realisation $j$ and $G_{S j}$ is the global similarity value for realisation $j$, as defined in Eq. (7).

The resulting map was defuzzified by multiplying each layer by the similarity value (Eq. 11) and taking the maximum resulting value:

$$
\begin{aligned}
P_{i}^{\text {flood }}= & \max \left[\left(1 \times V_{\mathrm{MOD}, \mathrm{i}_{\mathrm{high}}}\right),\left(0.6 \times V_{\mathrm{MOD}, \mathrm{i}_{\text {medium }}}\right),\right. \\
& \left.\left(0.3 \times V_{\mathrm{MOD}, \mathrm{i}_{\mathrm{low}}}\right),\left(0 \times V_{\mathrm{MOD}, \mathrm{i}_{\mathrm{no}}}\right)\right]
\end{aligned}
$$

Finally, the resulting map was normalised (Fig. 7) to give a relative indication of flood hazard. We have refrained from making this map look polished e.g. through smoothing or contours as this map best reflects the resolution of the modelling exercise, although for communication with stakeholders and the public such a map may have to be further processed.

A close examination of Fig. 7 reveals that, even after the conditioning on observations and choice of behavioural models, the predicted flood hazard is not always highest in the cells which contain river reaches. This seems to be an unexpected result as the river channel is always the lowest point locally. However, it is part of the implementation of the LISFLOOD model that water in the channel is routed independently from the floodplain, but allows for interaction between the two without the channel itself being directly part of the floodplain cell. This means that there can be water in the channel but not on the surrounding flood plain. Moreover, in this model the cell topography is averaged over the area of the cell and thus does not necessarily reflect the lowest elevations in a particular cell. In addition, a cell which has a depth of inundation of less than $10 \mathrm{~mm}$ (this could be altered and improved by a finer resolution) at the end of a time step is treated as still dry for the purposes of calculating the exchange between floodplain cells and between floodplain and river reaches. For these reasons it is possible that where the discharge is predominantly within the river, the cell containing the river might be treated as not inundated.

It can also be seen that some areas predicted as having a high inundation hazard are "disconnected" from the river (for example within the circle labeled 1 in Fig. 7). This might again be a result of the way in which LISFLOOD is implemented as outlined above, or possibly as a result of inundation from different directions in different model parameterizations, such that any particular pathway leading to flooding of that area (depression) does not have a particularly high hazard, especially if this is due to depths of less than $10 \mathrm{~cm}$ in 
Table 3. Possible explanation for the equifinality and optima of the model factors.

\begin{tabular}{|c|c|c|}
\hline Parameter & Equifinality & Explanation \\
\hline Floodplain Roughness & Yes & $\begin{array}{l}\text { Floodplain roughness has been shown to be insensi- } \\
\text { tive in earlier applications of this model (Hunter, 2006). } \\
\text { Thus it may be intrinsic in the model structure. The } \\
\text { channel is probably the main conveyance area for this } \\
\text { model reach. }\end{array}$ \\
\hline Channel Roughness & No & $\begin{array}{l}\text { The model structure forces the channel to be the main } \\
\text { conveyance area, therefore, some sensitivity can be ex- } \\
\text { pected. The sensitivity of in bank flow to peak flow con- } \\
\text { ditions has been illustrated by Roux and Dartus (2006). }\end{array}$ \\
\hline River width & Yes & $\begin{array}{l}\text { Variation may be too small in comparison with the } \\
\text { channel roughness. }\end{array}$ \\
\hline Outflow Roughness & No & $\begin{array}{l}\text { The inundation at the downstream end is probably a } \\
\text { main control factor of the performance measure. How- } \\
\text { ever, this tendency is in the broad spread and not in the } \\
\text { maximum values. }\end{array}$ \\
\hline Inflow Magnitude & Yes & $\begin{array}{l}\text { This equifinality may be explained by a dominat- } \\
\text { ing/compensating effect of channel roughness in con- } \\
\text { nection with channel depth. However, no two- } \\
\text { dimensional relationships could be detected. It could } \\
\text { be also due to undetected numerical errors., }\end{array}$ \\
\hline Initial error on first cross-section & Yes & $\begin{array}{l}\text { The depth of the upstream cross-section is not important } \\
\text { for the inundation extent. }\end{array}$ \\
\hline Standard deviation for cross-section error & No & $\begin{array}{l}\text { Channel depth controls the time of over-topping and } \\
\text { therefore has significant influence on the amount of wa- } \\
\text { ter on the flood-plain. The preference for small errors } \\
\text { may lie in the implementation of the numerical solution. }\end{array}$ \\
\hline
\end{tabular}

Table 4. Summary of estimation of 1st order sensitivity after the Sobol measure (without quantifying non-linear interacting sensitivities). Only the roughness of the channel exhibits and the standard deviation of the cross-section exhibits sensitivity. The entry 'Sensitive means that the parameter has been identified as being sensitive with this performance measure. For example, for the false alarm rate performance measure, the roughness of the channel has been identified as sensitive whereas the standard deviation of the cross-section has not.

\begin{tabular}{|c|c|c|c|}
\hline Performance Measure & Standard deviation of cross-section error & Channel Roughness & Other Parameters \\
\hline Hit Rate & Sensitive (SOBOL: 0.08) & Sensitive (SOBOL: 0.17) & \multirow{9}{*}{ 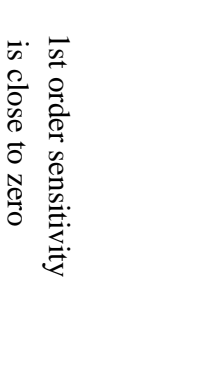 } \\
\hline Accuracy & Sensitive $(\mathrm{SOBOL} \cdot 0.06)$ & Close to zero & \\
\hline False Alarm Rate & Close to zero & Sensitive (SOBOL: 0.16) & \\
\hline Odds & Close to zero & Close to zero & \\
\hline Threat Score & Sensitive (SOBOL: 0.07) & Sensitive (SOBOL: 0.17) & \\
\hline Modified Threat Score & Sensitive (SOBOL: 0.05) & Close to zero & \\
\hline Bias & Sensitive (SOBOL: 0.07) & Sensitive (SOBOL: 0.29) & \\
\hline Pierce Skill Score & Sensitive (SOBOL: 0.07) & Sensitive (SOBOL: 0.13) & \\
\hline Fuzzy Measure & Sensitive (SOBOL: 0.1) & Close to zero & \\
\hline
\end{tabular}

the intervening area. It also is surprising that the downstream part of this section of river does not have a higher flood risk as it was clearly flooded in this event (circle number 2 in Fig. 7). Earlier studies (Pappenberger et al., 2006a) indicate also low hazard in this area. We therefore, conclude that this may be intrinsic in the data used to set up the model leading to a low predicted risk despite the fact that this area was actually flooded. This is indicative of the general problem of flood hazard mapping in that it is very difficult to reproduce the observed inundation extent in all areas of the floodplain (Pappenberger et al., 2007). 


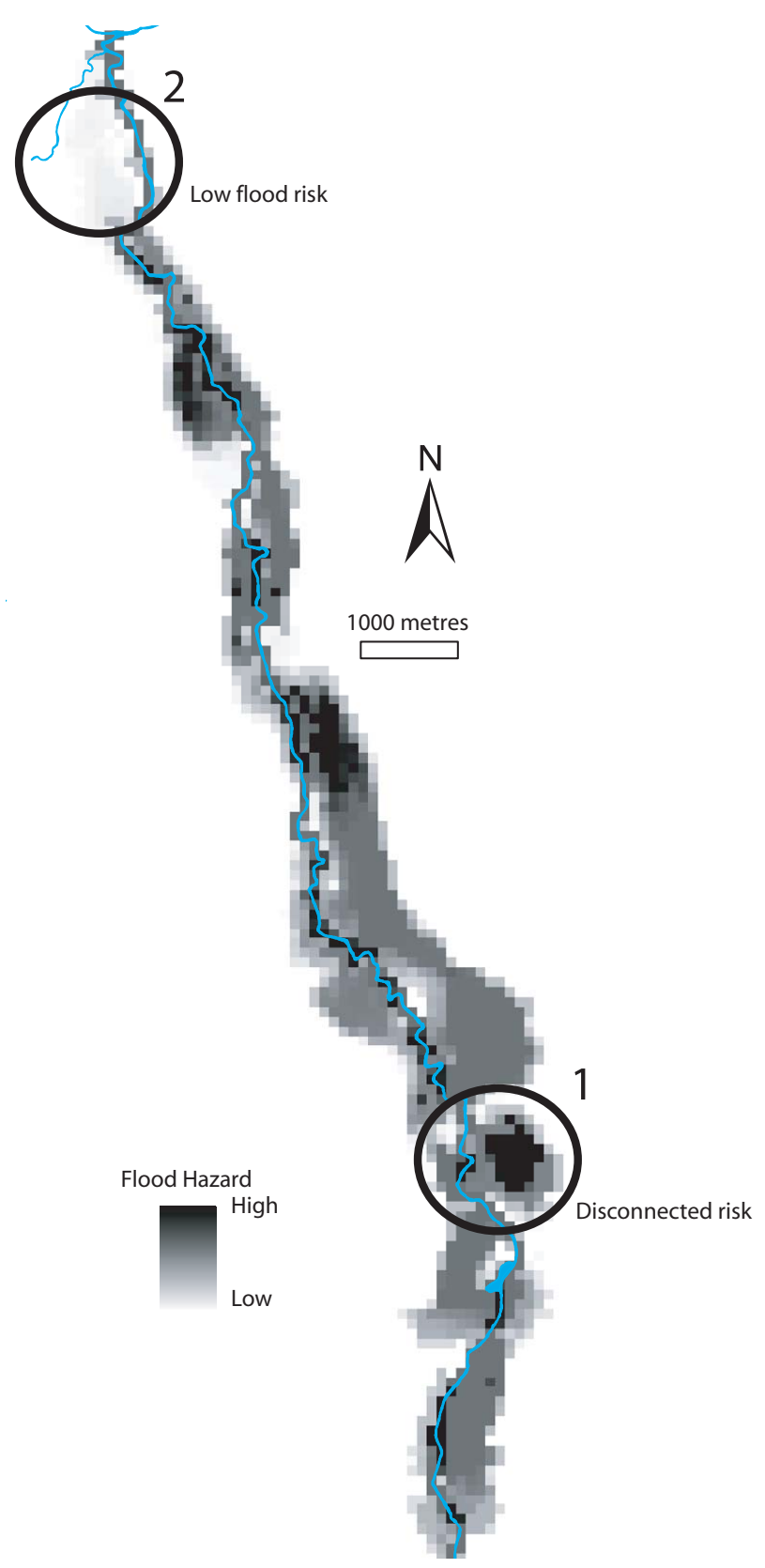

Fig. 7. An inundation likelihood map for Alzette created from conditoning LISFLOOD-FP on a fuzzy representation of the SAR data using the fuzzy performance measure.

This example map demonstrates that it is possible to derive a flood hazard map from a performance measure which takes account of incommensurability and observational error. The advantage of this methodology over traditional approaches is that it can take account of the errors more explicitly. The disadvantage is that it is computationally more demanding.

\section{Conclusions}

A new fuzzy based technique to analyze the spatial predictions of flood inundation models is explored that explicitly recognizes the uncertainty in the observed data and includes commensurability error in the model evaluation. Raster maps consisting of fuzzy category vectors can provide a more accurate representation of SAR images than discrete binary category maps as they enable the retention of information relating to the likelihood of inundation at any location on a floodplain. When combined with a suitable function that fuzzifies the predictions of a 2-D inundation model, a performance measure based on fuzzy map comparison techniques can be applied. A practical application of the technique to a short section of the Alzette River, Luxembourg reveals a strong correlation between the novel fuzzy based measure and existing discrete measures. The methodology has been shown to be particularly useful when uncertain remote sensing information exists.

The comparison of the fuzzy and classical performance measures indicates that taking into account the uncertainty of the spatial observations by means of fuzzified inundation areas results in larger dispersion of the performance measure (Fig. 5). The GSA also confirms lower sensitivity of the fuzzy measure in comparison with crisp equivalents (Table 4). This result is expected as the uncertainty of model predictions should increase when the uncertainty of observations is taken into account. However, despite of larger scatter of the predictions (Figs. 5 and 6), as well as the floes inherent to the applied LISFLOOD-FP model, the resulting inundation map is realistic. The introduction of fuzzy, i.e. subjective measure into the process of the derivation of risk maps gives the possibility of applying localized subjective judgment regarding the validity of the observations, including eye witness and other available qualitative ("soft") information about the flood extent. Thus fuzzy approach in combination with subjective weighting of the risk (Pappenberger et al., 2006b) will lead to more realistic and "humanized" risk maps.

We want to note here that no performance measure should be used in isolation and should ideally be embedded into a multi-objective calibration framework in order to capture the capability of each measure to evaluate the performance of various features. Therefore, future research should include measured water levels and eye witness accounts as it has been indicated by research elsewhere that these have a higher discriminatory power than inundation patterns (Mignot et al., 2006; Werner et al., 2005a; Werner, 2004).

Acknowledgements. We would like to thank G. Müller of the Service de la Gestion de l'Eau for providing some of the data used in this study. This study would have been impossible without the help of P. Bates (Professor of Hydrology, Bristol University) and N. Hunter (Bristol University). F. Pappenberger and R. Romanowicz have been funded by the Flood Risk Management Research Consortium (FRMRC) which is supported by Grant 
GR/S76304 from the Engineering and Physical Sciences Research Council, in partnership with the Natural Environment Research Council, the DEFRA/EA Joint Research Programme on Flood and Coastal Defence, UKWIR, the Scottish Executive and the Rivers Agency (N.I.). This financial support is gratefully acknowledged. Development of extensions to the GLUE methodology has been supported by NERC grant NER/L/S/2001/00658 awarded to K. Beven. We thank N. Hunter (Bristol University), S. Néelz (Heriot-Watt University) and one anonymous reviewers for their comments, which helped to greatly improve this paper.

Edited by: J. Freer

\section{References}

Aronica, G., Bates, P. D., and Horritt, M. S.: Assessing the uncertainty in distributed model predictions using observed binary pattern information within GLUE, Hydrolog. Processes, 16(10), 2001-2016, 2002.

Aronica, G., Hankin, B., and Beven, K. J.: Uncertainty and equifinality in calibrating distributed roughness coefficients in a flood propagation model with limited data, Adv. Water Resour., 22(4), 349-365, 1998.

Bates, P. D. and De Roo, A. P. J.: A simple raster-based model for flood inundation simulation, J. Hydrol., 236(1-2), 54-77, 2000.

Bates, P. D., Horritt, M. S., Aronica, G., and Beven, K.: Bayesian updating of flood inundation likelihoods conditioned on flood extent data, Hydrol. Processes, 18(17), 3347-3370, 2004.

Bates, P. D., Wilson, M., Horritt, M., Mason, D., Holden, N., and Currie, A.: Reach scale floodplain inundation dynamics observed using airborne synthetic aperture radar imagery: Data analysis and modelling, J. Hydrol., 328(1-2), 306-318, 2006.

Beven, K. J.: A manifesto for the equifinality thesis, J. Hydrol., 320(1-2), 18-36, 2006.

Beven, K. J. and Binley, A.: The future of distributed models - model calibration and uncertainty prediction, Hydrolog. Processes, 6(3), 279-298, 1992.

Cheng, T., Molenaar, M., and Lin, H.: Formalizing fuzzy objects from uncertain classification results, Int. J. Geographical Information Science, 15(1), 27-42, 2001.

Dilley, M., Chen, R. S., Deichmann, U., Lerner-Lam, A. L., and Arnold, M.: Natural Disaster Hotspots: A Global Risk Analysis, World Bank, The, U.S., 150 pp, 2005.

ESA: European Space Agency, EnviSat ASAR Product Handbook, Issue 1.2 (http://envisat.esa.int/dataproducts/asar/CNTR. htm), 2004.

Hagen, A.: Fuzzy set approach to assessing similarity of categorical maps, International Journal of Geographical Information Science, 17(3), 235-249, 2003.

Hardy, R. J., Bates, P. D., and Anderson, M. G.: The importance of spatial resolution in hydraulic models for floodplain environments, J. Hydrol., 216(1-2), 124-136, 1999.

Horritt, M. S.: A statistical active contour model for SAR image segmentation, Image and Vision Computing, 17, 213-224, 1999.

Horritt, M. S.: A methodology for the validation of uncertain flood inundation models, J. Hydrol., 326(1-4), 153-165, 2006.

Horritt, M. S. and Bates, P. D.: Predicting floodplain inundation: raster-based modelling versus the finite-element approach, Hydrol. Processes, 15(5), 825-842, 2001.
Horritt, M. S. and Bates, P. D.: Evaluation of 1D and 2D numerical models for predicting river flood inundation, J. Hydrol., 268(14), 87-99, 2003.

Horritt, M. S., Mason, D. C., and Luckman, A. J.: Flood boundary delineation from Synthetic Aperture Radar imagery using a statistical active contour model, Int. J. Rem. Sens., 22(13), 24892507, 2001.

Hunter, N. M.: Flood Inundation Modelling - PhD Thesis, School of Geography, Bristol University, Bristol, 2006.

Hunter, N. M., Bates, P. D., Horritt, M. S., De Roo, P. J., and Werner, M. G. F.: Utility of different data types for calibrating flood inundation models within a GLUE framework, Hydrol. Earth Syst. Sci., 9, 412-430, 2005a.

Hunter, N. M., Horritt, M. S., Bates, P. D., Wilson, M. D., and Werner, M. G. F.: An adaptive time step solution for raster-based storage cell modelling of floodplain inundation, Adv. Water Resour., 28(9), 975-991, 2005b.

IRMA: FRHYMAP - flood risk scenarios and hydrological mapping, Final report of the IRMA-SPONGE Project, EC, 2002.

Kavetski, D., Kuczera, G., and Franks, S. W.: Calibration of conceptual hydrological models revisited: 1 . Overcoming numerical artefacts, J. Hydrol., 320(1-2), 173-186, 2006.

Leopardi, A., Oliveri, E., and Greco, M.: Two-dimensional modeling of floods to map risk-prone areas. Journal of Water Resources Planning and Management-Asce, 128(3), 168-178, 2002.

Matgen, P., Henry, J.-B. F., Pappenberger, F., Pfister, L., de Fraipont, P., and Hoffmann, L.: Uncertainty in calibrating flood propagation models with flood boundaries derived from synthetic aperture radar imagery, XXth ISPRS Congress, International Society for Photogrammetry and Remote Sensing, Istanbul, Turkey, 2004.

Matgen, P., Schumann, G., Henry, J. B., Hoffmann, L., and Pfister, L.: Integration of SAR-derived river inundation areas, highprecision topographic data and a river flow model toward near real-time flood management, Int. J. Appl. Earth Obs. Geoinformation, in press, 2007.

Mignot, E., Paquier, A., and Haider, S.: Modeling floods in a dense urban area using 2D shallow water equations, J. Hydrol., 327(12), 186-199, 2006.

Pappenberger, F. and Beven, K. J.: Ignorance is bliss - or 7 reasons not to use uncertainty analysis, Water Resour. Res., 42(5), W05302, doi:10.1029/2005WR004820, 2006.

Pappenberger, F., Beven, K. J., Horritt, M. S., and Blazkova, S.: Uncertainty in the calibration of effective roughness parameters in HEC-RAS using inundation and downstream level observations, J. Hydrol., 302, 46-69, 2005.

Pappenberger, F., Matgen, P., Beven, K. J., Henry, J.-B., Pfister, L., and de Fraipont, P.: Influence of uncertain boundary conditions and model structure on flood inundation predictions, Adv. Water Resour., 29(10), 1430-1449, 2006a.

Pappenberger, F., Matgen, P., Beven, K. J., Henry, J.-B., Pfister, L., and de Fraipont, P.: Influence of uncertain boundary conditions and model structure on flood inundation predictions, Adv. Water Resour., 29(10), 1430-1449, 2006b.

Pappenberger, F., Beven, K. J., Frodsham, K., Romanowicz, R., and Matgen, P.: Grasping the unavoidable subjectivity in calibration of flood inundation models: A vulnerability weighted approach, J. Hydrol., 333(2-4), 275-287, 2007.

Power, C., Simms, A., and White, R.: Hierarchical fuzzy pattern 
matching for the regional comparison of land use maps, Int. J. Geographical Information Science, 15(1), 77-100, 2001.

Ratto, M., Saltelli, A., Tarantola, A., and Young, P.: Improved and accelerated sensitivity analysis using State Dependent Parameter models, Sensitivity Analysis of Model Output, Santa Fe, New Mexico, 8-11 March 2004.

Romanowicz, R. and Beven, K. J.: Estimation of flood inundation probabilities as conditioned on event inundation maps, Water Resour. Res., 39(3), 1073, doi:10.1029/2001WR001056, 2003.

Romanowicz, R., Beven, K. J., and Tawn, J.: Bayesian calibration of flood inundation models, in: Floodplain Processes, edited by: Anderson, M. G., Walling, D. E., and Bates, P. D., John Wiley \& Sons, New York, pp. 333-360, 1996.

Romanowicz, R. J. and Macdonald, R.: Modelling Uncertainty and Variability in Environmental Systems, Acta Geophysica Polonica, 53, 401-417, 2005.

Roux, H. and Dartus, D.: Use of parameter optimization to estimate a flood wave: Potential applications to remote sensing of rivers, J. Hydrol., 328(1-2), 258-266, 2006.

Saltelli, A., Tarantola, A., Campolongo, F., and Ratto, M.: Sensitivity Analysis in Practice - A Guide to Assessing Scientific Models, John Wiley \& Sons, Chichester, 2004.
Schumann, G., Henry, J. B., Hoffmann, L., Pfister, L., Matgen, P., and Pappenberger, F.: Demonstrating the high potential of remote sensing in hydraulic modelling and near real-time flood risk management, RSPSoc and NERC Eartch Observation conference, 6-9 Septemer 2005, University of Plymouth, 2005.

Thieken, A. H., Muller, M., Kreibich, H., and Merz, B.: Flood damage and influencing factors: New insights from the $\mathrm{Au}-$ gust 2002 flood in Germany, Water Resour. Res., 41(12), doi:10.1029/2005WR004177, 2005.

Werner, M., Blazkova, S., and Petr, J.: Spatially distributed observations in constraining inundation modelling uncertainties, Hydrol. Processes, 19(16), 3081-3096, 2005a.

Werner, M. G. F.: A comparison of flood extent modelling approaches through constraining uncertainties on gauge data, Hydrol. Earth Syst. Sci., 8(6), 1141-1152, 2004.

Werner, M. G. F., Hunter, N. M., and Bates, P. D.: Identifiability of distributed floodplain roughness values in flood extent estimation, J. Hydrol., 314(1-4), 139-157, 2005b.

Yu, D. and Lane, S. N.: Urban fluvial flood modelling using a twodimensional diffusion-wave treatment, part 2: development of a sub-grid-scale treatment, Hydrol. Processes, 20(7), 1567-1583, 2006. 